\title{
Historical Development of Liquid Crystalline Stationary Phases: An Overview
}

\author{
Emad Ghanem \\ Department of Chemistry, Faculty of Sciences, Damascus University, Damascus, Syrian Arab Republic
}

Email address:

ganememad@yahoo.com

To cite this article:

Emad Ghanem. Historical Development of Liquid Crystalline Stationary Phases: An Overview. American Journal of Applied Chemistry.

Special Issue: Development of Liquid Crystalline Stationary Phases for Liquid and Gas Chromatographic Separations.

Vol. 3, No. 5-1, 2015, pp. 7-10. doi: 10.11648/j.ajac.s.2015030501.12

\begin{abstract}
Nematic liquid crystals have shown particular selectivity and sensitivity as stationary phases for the separation of isomers having similar volatilities. Because of their unique selectivity towards rigid solute isomers, liquid crystal stationary phases were considered at one time to be a very promising class of materials that give the gas chromatographic separations a great deal of attention. In this overview, we present a brief historical view of the liquid crystal stationary phases development, which were successfully used in gas chromatography for separation of isomers.
\end{abstract}

Keywords: Liquid Crystal, Chromatography, Stationary Phase, Separation, Nematic

\section{Introduction}

Chemical analyses of environmental contamination, and quantifying known tracer compounds in these complex organic mixtures, can provide insight into biological and chemical degradation processes $[1,2]$ and contaminant sources [3-6].

Over the past decades, a variety of liquid and gas chromatographic techniques have been proved with great success to improve understanding of pollutants in intricate natural systems.

For example, Hydrocarbons considered important industrial raw materials, semi-products, and products as well as significant pollutants in our environment [7]; therefore, analytical chemistry dedicates permanent attention to the development of new methods of their analysis.

The detailed analysis of individual hydrocarbon isomers can also be important, because they show different reactivity, and provide products of different quality, or individual isomers can show a different degree of biological activity or toxicity.

In the plastic industry, industrial applications have led to the development of a variety of studies that focus on the use of new materials. These studies have the objective of optimizing existing processes that seek to obtain pure isomers. These isomers have similar physicochemical properties, and the process of producing pure isomers is intricate.

Thus, increasing requirements to analyze these isomeric compounds assert the importance of suitable study of separation systems, and methods of their individual identification.

Increasing attention in industry has been also focused on important pollutants and phenols introduced into the environment through the discharge of industrial wastes, and the decomposition of various pesticides and herbicides [8-10].

While the determination of phenolic isomers by ordinary stationary phases presented some difficulties; these isomers have similar boiling points and polarities, thus, searching for better stationary phases including highly selective ones was an important trend of Gas Chromatography (GC) development.

Generally, a stationary phase must fulfill certain basic requirements in GC. It must be chemically inert, non-volatile and thermally stable. Furthermore, it must has a dissolution power, and a possible selectivity for the sample components to be separated [11]. Because, the stationary phase must allow rapid diffusion of the solutes, the rapid exchange of analytes between the stationary and mobile phases is a presupposition for high separation efficiency in capillary GC.

Among the various stationary phases that have been studied in GC, liquid crystal compounds remain one of the most interesting materials used as stationary phase in gas liquid chromatography. Their exceptional behavior allowed 
their application in the analysis of numerous mixtures of components. Such applications towards the separation of isomeric phenols, naphthalene homologs, polycyclic aromatic hydrocarbons, di-substituted benzenes, and volatile oil constituents [12-16] have been widely investigated.

\section{Liquid Crystals}

Liquid crystalline (LC) compounds have been developed into a very useful class of materials $[17,18]$. Both small molecules with mesogenic properties and polymers, which may show LC behavior due to the main chain configuration, or be substituted with mesogenic groups are used. Liquid crystalline phases occur where, above the melting point, but some molecular order is retained in the fluid. In general, they are formed from compounds that have elongated, and rod-like molecules.

Thermotropic LCs display this behavior as a function of temperature, and some of the molecular arrangements. For many applications, polymeric LCs are preferred for their better thermal stability and/or ease of processing. Other applications demand LCs dissolved in a polymer or carrier; these include dyes, coatings and films.

Some years ago, LCs and LC polymers were suggested as stationary phases for analytical gas chromatography where the molecular ordering of the LCs should allow discrimination between closely related isomeric analytes. For each of these applications, understanding of the interactions between the components, is important in designing and formulating new systems.

\section{Development of Nematic Liquid Crystalline Stationary Phases (LCSPs)}

Witkiewicz [19] reviewed in his works the usefulness of LCSPs for the separation of various compounds. The mixtures of different isomers have been separated on liquid crystalline stationary phases, and the results obtained so far have been superior to those obtained on conventional stationary phases [20].

Kelker [21, 22] was first who compared the relative retention of a para-xylene/meta-xylene mixture on four nematic stationary phases in GC, and he observed that the selectivity is higher with liquid crystals of wider nematic range. Simultaneously, Dewar and Shröeder [23] attempted a similar correlation between maximum selectivity and nematic ranges with data on eight gas chromatographic nematic phases, expectations were apparent. Although this empirical approach is partially successful, it is not theoretically justified, since the nematic range depends on the crystal-nematic transition temperature, and this, in turn, does not show regular trends for mesomorphic compounds.

Since then, stationary phases of liquid crystals in GC have been intensively used because of their unique selectivity and physicochemical properties [24]. The remarkable shape selectivity exhibited by such phases is closely related to the parallel molecular alignment of the mesophase molecules that exercise preferential solubility for rigid linear molecules and steric discrimination against bulky molecules.

Generally, most separations reported in the previous studies were obtained with low-temperature nematic liquid crystals for the separations of predominantly isomeric substituted benzenes. These phases provided separations for wide varieties of solute mixtures, especially for solutes which are difficult to resolve on conventional stationary phases.

To date, a large number of LCSPs have been synthesized, and the structural requirements for giving liquid crystalline phases have generally been well understood [25-28].

\subsection{Separation Technique}

In 2005, Witkiewicz et al. [27] reviewed their analytical applications and advancement made in both techniques of high performance liquid chromatography and gas chromatography. Because of the rode-like shape and the orientational order provided by the anisotropy of the liquid crystal, distinctive solvent property is revealed from this material.

Recently, we have reviewed a comparative analytical study for the separation of isomers on nematic LCSPs [28].

Mainly, separations are yielded based on variations in molecular shape (length-to-breadth ratio and planarity) independently on any specific interactions [29-32].

On conventional capillary columns, discrimination between positional or geometrical isomers is difficult to achieve because of their similar physical properties.

On the contrary, every liquid crystalline stationary phase enables its effective and selective way of separation. For two solutes with the same boiling point, the solute with the greater length-to-breadth ratio will be retained longer on the LCSP.

Better understanding of the relationship between the molecular structure of liquid crystal and its analytical properties, would enable a more rational selection of the liquid crystalline stationary phase to resolve various analytical problems.

Thus, for different materials, mesophases which have the same structure may exhibit different chromatographic properties towards the same mixtures of components.

Therefore, the molecular structure of these compounds influences significantly the separation process that takes place on a LCSP.

Numerous workers have been studying the effect of the presence of lateral substituents on the analytical properties of the LCSPs [33-38]. It is pointed out that compounds with higher nematic range exhibit better selectivity [39]; however, the presence of lateral substituent on mesogenic structure leads to a decrease in nematic range and phase selectivity (with regard to isomers especially) by increasing the intermolecular distances in the mesophase, which reduce the steric effect responsible for the selectivity within the mesophase [40]. In other researches, it is indicated that certain lateral substituents may decrease the nematic range but may yield a higher selectivity, and thus a better separation $[34,35]$.

In all cases, synthesizing laterally substituted liquid crystals 
with higher nematic range and selectivity remains one of the principal parts in the development of these materials.

\subsection{Physicochemical properties of LCSPS}

Physicochemical properties of LCs on their behavior as stationary phases in a chromatographic column are still necessary.

Investigations of LCSPs properties by inverse gas chromatography (IGC) has a particular advantage. To rely on the results of such investigations entirely, comparative studies by IGC and conventional methods for examining liquid crystals, e.g., differential scanning calorimetry (DSC), nuclear magnetic resonance (NMR) and Fourier transform infrared spectroscopy (FTIR), are also necessary [41].

In all techniques used for liquid crystalline characterization, $\mathrm{X}$-ray scattering is by far the most useful one for probing the packing structures of liquid crystalline. In particular, X-ray scattering study of such oriented molecules, enables us to obtain much important information on orientational and positional order of the molecular arrangements of LCs, which are essential for understanding their packing structures.

\section{Acknowledgements}

We acknowledge our sincere thanks to Department of Chemistry, Faculty of Sciences in University of Damascus.

\section{References}

[1] M. Megharaj, B. Ramakrishnan, K. Venkateswarlu, N. Sethunathan, R. Naidu, Environ Int, vol. 37, PP. 1362-1375, 2011.

[2] B.R. Simoneit BR, Mass Spectrom Rev, vol. 24, PP. 719-765, 2005.

[3] M.P. Fraser, K. Lakshmanan, Environ Sci Technol, vol. 34, PP. 4560-4564, 2000.

[4] M.A. Mazurek, Environ Health Perspect, vol. 110, PP. 995-1003, 2002.

[5] J.J. Schauer, W.F. Rogge, L.M. Hildemann, M.A. Mazurek, G.R. Cass, Atmos Environ, vol. 30, PP. 3837-3855, 1996.

[6] B.J. Williams, A.H. Goldstein, N.M. Kreisberg, S.V. Hering, D.R. Worsnop, I.M. Ulbrich, K.S. Docherty, J.L. Jimenez, Atmos Chem Phys, vol. 10, PP. 11577-11603, 2010.

[7] WL. Jr. Zielinski, CRC handbook of chromatography: hydrocarbons, vol. 1. Gas chromatography. CRC Press, Inc., Boca Raton. 1987.

[8] K.P. Naikwadi, P.P. Wadgaonkar, J Chromatogr A, vol. 811(1-2), PP. 97, 1998.

[9] L.E. Cook, R.C. Spangelo, Anal Chem, vol. 46(1), PP. 122-126, 1974.

[10] WL. Jr. Zielinski, G.M. Janini, J Chromatogr A, vol. 186, PP. 237-247, 1979.

[11] H. Rotzsche, Stationary phases in gas chromatography. J
Chromatogr Library, vol. 48, Elsevier, Amsterdam. 1991.

[12] P. Berdagué, F. Perez, J. Courtieu, J.P. Bayle,O. Abdelhadi, S. Guermouche, M.H. Guermouche, Chromatographia, vol. 40, PP. 581-586, 1995.

[13] A. Meddour, J. Courtieu, O. Abdelhadi, S. Guermouche, M.H. Guermouche, Chromatographia, vol. 43, PP. 387-392, 1996.

[14] J.P. Bayle, Chromatographia, vol. 50, PP. 338-345, 1999.

[15] D. Bélaïdi, S. Sebih, S. Boudah, M.H. Guermouche, J.P. Bayle, J Chromatogr A, vol. 1087, PP. 52-56, 2005.

[16] M. Dahmane, F. Athman, S. Sebih, M.H. Guermouche, J.P. Bayle, S. Boudah, Chromatographia, vol. 70, PP. 489-495, 2009.

[17] C.B. McArdle, Side chain liquid crystal polymers. Blackie, London. 1989.

[18] P.J. Collings, Liquid crystals: Nature's delicate phase of matter. Hilger Bristol. 1990.

[19] Z. Witkiewicz, Liquid crystals: applications and uses. World Scientific Publishing, Singapore. 1991.

[20] Z. Witkiewicz, J. Mazur, Liq Chromatogr Gas Chromatogr, vol. 8, P. 224, 1990.

[21] H. Kelker, Z Anal Chem, vol. 198, PP. 254-266, 1963.

[22] H. Kelker, E. Von Schivizhoffen, Advances in chromatography, vol. 6. Marcel Dekker, New York. PP. 247-297, 1968.

[23] M.J.S. Dewar, J.P. Shröeder, J Am Chem Soc, vol. 86, PP. 5235-5239, 1964.

[24] F. Perez, P. Berdague, J.P. Bayle, J. Courtieu, S. Boudah, M.H. Guermouche, J High Resolut Chromatogr, vol. 20, PP. 379-384, 1997.

[25] F. Gritti, G. Felix, Chromatographia, vol. 55, P. 523, 2002.

[26] Z. Witkiewicz, J. Oszczudłowski, M. Repelewicz, Chem Anal (Warsaw), vol. 48, P. 397, 2003.

[27] Z. Witkiewicz, J Chromatogr A, vol. 1062, PP. 155-174, 2005.

[28] E. Ghanem, H. Sahar, Chromatograpia, vol. 77(9-10), PP. 653-662, 2014.

[29] J. Coca, I. Medina, S.H. Langer, Chromatographia, vol. 25, PP. $825-830,1988$.

[30] G. Chiavari, L. Pastorelli, Chromatographia, vol. 7, PP. 30-33, 1974.

[31] D.E. Martire, P.A. Blasco, P.F. Carone, L.C. Chow, H. Vicini, J Phys Chem, vol. 72, PP. 3489-3495, 1968.

[32] A.E. Habboush, S.M. Farroha, A.Y. Kreishan, J Chromatogr A, vol. 664, 71-76, 1994.

[33] M.J.S. Dewar, J.P. Schroeder, J Org Chem, vol. 30, PP. 3485-3490, 1965.

[34] K.P. Naikwadi, D.G. Panse, B.V. Bapat, B.B. Ghatge, J Chromatogr A, vol. 195, PP. 309-316, 1980.

[35] K.P. Naikwadi, D.G. Panse, B.V. Bapat, B.B. Ghatge, J Chromatogr A, vol. 206, PP. 361-367, 1981. 
[36] K.P. Naikwadi, S. Rokushika, H. Hatano, J Chromatogr A, vol. 331, PP. 69-76, 1985.

[37] F. Athman, M. Dahmane, S. Boudah, M.H. Guermouche, J.P. Bayle, S. Sebih, Chromatographia, vol. 70, PP. 503-510, 2009.

[38] M. Dahmane, F. Athman, S. Sebih, M.H. Guermouche, J.P. Bayle, S. Boudah, J Chromatogr A, vol. 1217, PP. 6562-6568, 2010.
[39] J.P. Schroeder, G.W. Gray, P.A. Winsor, Liquid crystals and plastic crystals. Ellis Horwood, Chichester. p 361, 1974.

[40] A. Ziolek, Z. Witkiewicz, R. Dabrowski, J Chromatogr A, vol. 294, PP. 139-154, 1984.

[41] F. Gritti, G. Félix, M.F. Achard, F. Hardouin, J Chromatogr A, vol. 893, PP. 359-366, 2000. 